\title{
The Artistic directions in stalactites of the antiquarian and religious buildings minarets
}

\author{
AlAttabi furat J. Hassan ${ }^{1, a,{ }^{*},}$ Muna K. A. Dwass ${ }^{2, b}$ \\ ${ }^{1}$ College of Fine Arts, University of Baghdad, Iraq \\ ${ }^{2}$ College of Fine Arts, University of Baghdad, Iraq \\ aemail: furathassan@gmail.com \\ ${ }^{*}$ Corresponding author
}

Keywords: Artistic, directions, stalactites, antiquarian, minarets.

\begin{abstract}
The research aims to study the artistic directions in stalactites of the antiquarian and religious buildings minarets in Baghdad, Because of this architectural element of architectural and beauty benefits, the architectural side has a significance in transferring the building from square to octagon or another geometric shape, or strengthening of the wall or the foundation that minaret or dome had been built on. The beauty side includes decorative terms that put in the last level of the building progress, and it works on showing the stalactites in a several decorative shapes and directions and designing foundations in deferent ways of fulfillment.
\end{abstract}

\section{Introduction}

The absence of the Islamic artist from drawing art and personification because the hatred that in the Islamic belief, the decorative had been considered as alternative of that in the all life spaces as the architectural and calligraphic paintings as well as the decorative of covers and pages of the holly Quran.

And we realize from that that the decorative started in adornment of the Islamic architecture what can be suitable with the it's place and what it has privacy, beliefs and the thoughts of the Muslim person. Such as shrines and mosques. All that developments had been entered in a very clear way through Abbasid era. The Muslim artist didn't get enough from making that architecture more beautiful of the outside shape. He went inside to give the shape beauty and lustrine, and he started to interfered in the architectural shape of it and changes it from a situation to another as much as it can be suitable to the benefit of the beauty and architectural. From that starting it appeared in its architectural and beauty shape, the architectural is to transfer the building from square to circular or octagon or any other geometrical shape, and the heaviness distribution on different directions equal proportions. while the beauty that represents of the stalactite shape establishment and make it suitable with the external and internal space that puts in the last level of the building progress which it has an affection on the stalactite appearing in different shapes and directions (designing) as well as the variation of the used ores nature, and throughout what we talked about the researcher formulated her research problem by wondering the following : what are the artistic directions of the stalactites of the religious and heritage buildings minarets. That's why the First part following wonderings appeared:

1. The placement way of the decorative terms on stalactite.

2. Spread of the decorative artistic directions in creates of the beauty dimension of the stalactite.

3. Differences are occurred between the internal and external decorative; because of what the internal decorative has a special privacy in the designing way and placement of the used ores.

4. Absence of geometric and artistic analysis for the stalactites designing.

Second Part of research acquire the importance of the stalactites itself in transferring of the architecture shape from a situation to another, by the way the stalactites have special privacy that defers from the privacy of the elements of design in Arabic and Islamic architecture in a very rare 
way through the ways of placements, designing and the primary material that can be used to make that decorative in a plastic unite that considered as a beauty value, which has its special system in establishing and placement, the stalactites research contains two sides, the first one is architectural which has a structural benefit . the second one is a beauty that raises throughout two sides : the first one throughout using of the half circular cavities and inverted triangles or the second one throughout the using of the decorative that made for that stalactites or what joins it .Plus the decorative using in a deferent technical some of them : such as Baghdad city minarets .

\section{RESEARCH GOALS}

The research aims to know the artistic directions of the stalactites of the religious and heritage buildings minarets throughout the following:

1. The design styles of the stalactites of the religious building minarets.

2. The geometrical foundations to build the minarets stalactites.

3. The artistic directions and the used ores in the stalactites of the heritage and religious buildings.

\section{1 "A historical brief about the stalactite origin}

The views of scientists and researchers have varied about the origin of the stalactite and its history, and throughout our researches about the stalactite term in the Arabic sources we find that it represents the man situation as he sits squatting,

And it had been said that Arabs hate what the Greeks like on soft surface and square angles they were making the small skylights which were hanging all each other as a gradual geometric swinging. It reminds us in hives that called stalagmite which ups from the cave floor the artistic Europe historians named it as stalactites which means calcareous deposits that hanging from some caves beneath. It was rumored too by the Europeans who were busy in Islamic monuments field to the indication of all images of that ornamental architecture element. Now its name refers to a single kind of stalactites which has indications that used in many of domes, but it had been taken as a decorative way for the doors and windows holes, necklace, entrance, corners, nooks, minarets balconies and everywhere in building that can be suitable for that ornamental element in the fifth hegira century (the eleventh ad century).

\subsection{Squinches (the triangular stalactites)}

That can be the reason of its uses and its appearance justification in domes corners that are built on square rooms which called (squinches), which can be used to form a gradient mood to move the torques to the side walls not to the square corner that had been cancelled. The curves came as a replacement which we won't from it to prepare the octagon shape that had been established over the square room shape, to contain the base in the next level of the dome that agreed with it circular shape, squinches are the blocks with triangle shape, which its tops are lying beneath with curved . To the front in the above.

The geniality of the Muslims architectural Lies and characterized by the other architectural schools in its pedantry and the organic. Innovations When it could to adapt and transfer this structural element to an artistic world and the beauty system for the architectural without any trouble, it consistent with the abstract approach that had been painted by the arts and the beauty elements that are aligned the creed are that search the spiritual of the things far away from the tangible appearance and it had been used in some of the UMAYYAD PALACES in sham city Like (ALHAMAM DOME) in (OMRAH PALACES)(93-97 H $\backslash 711-715$ ad) it can be one of the most worthy thing by attention. It's joining ornamental and architectural elements in the Islamic building in the Islamic building. And this is one of the most cases that have significance method that can hide so many applications and mathematic and geometric systems that caused the scientific revolution by Muslims which embodiment in all artistic and scientific life aspects. We can find the stalactite in the following positions of the buildings: 
1. In the fourth corners that lie under the domes in the building that have a square shape.

2. Beneath the minarets balconies it can be used under any place inside or outside building even it sculptured formula on wood or marble that the mosques platforms .

3. In a treatment of a kind of truly or fake necklaces that lie about some energies especially in MOROCCO and ANDALUS architecture.

4. In making of the poles' crowns from stone or woods.

5. It can be used in making ceilings inside the paths that lie between the curves and the parallel wall such as in the SHARABIA School or the ABBASID PALACE in Baghdad.

6. In the outside conical roofing that had repeated in the architecture of the graves and grave stone for the saints and selected ones of the people, in the architecture of SELJUK in the eleventh centaury AD, or to pad the conical domes in small Asia and Iran, the first example for the stalactite dome we can find it dome in front of houses such as ZUMURAD KHATOUN in Baghdad.

7. In the upper part of the inside empty polygon entrance because its moving to the entrance bowl (half dome) as in HASSAN SULTAN school entrance in Cairo that established in 1356AD . The domed rectangle entrance in Iraq and Iran we can find it in al ALJUMAA mosque in ASFAHAN.

8. The internal ornament treatments for domes such as some domes in al ALHEMRA PALACE that give a sight of a great harmony between the architectural track and the decorated shapes to give it beauty and symbolism.

There is several kind of the stalactite but we can find the most important kind in EGYPT named as (HALABI, SHAMI, BALADI, and BEDALAYA AND TRAINGLE). And because of the absence of the united Arabic term so that we find that there is a different name in each Arabic country for example in morocco the masters of the craft called each part of the seven part that the stalactite is made of which are : ALSHARABIA, TASNIA, ALSHAIRA OR ALSIRWALIA).

Usually gypsum and artificial stone can be used in structure of the marble flour in pouring and embodiment this kind of stalactites specially in Arab western > also we can find that in Egypt which they use the sculptured stone or less than that from wood and so on . That includes the building style in ALSHAM AND ALHIGAZ but in Iraq and less than it like in the Arab gulf they use the complex wood or the sculptured one to embodiment this element. also the kind that made from gypsum and covered by colored KASHANI or mirrors like the sacred threshold in Baghdad, najaf and Karbala which reveals high creativity that holds the breaths because the light reflection from all that mirrors.

\section{LITERATURE BACKGROUND}

\subsection{The arched stalactites}

Its represented by the Bert curvature corners so that it looks like halves domes around the square shape to transfer it into octagon shape after while it will be easy to make a circle shape that stands on the tips of the curvatures and on the middle of the square sides to the dome bases. This kind has a big role in forming of the ABBASID domes in Iraq.

Researches and archaeologists' had agreed that the human turned around of making the stalactite from the curvatures that we mentioned before. After that curvatures developed by doubling its curves then the stalactites appeared that deployed in the fifth century hejria. Some people think that the stalactites were been taken from the ups and downs. The researcher sees that the studying of the architectural origin of the stalactite was the previous researcher's dependence one on the other.

Another researchers said that the stalactite in Islamic art is skylight that take a place above the four corners of the square room which wanted to make a ceiling by the dome via these four skylight to make it possible to find a roof that can't be stable on it. The Arabs inherited that way and used it in their buildings but they developed it so that they divided it into several little skylight. they also worked of art by roofing and decorating it, till it looked a piece of beautiful art, while the researcher refers to stalactite origin is the way of making cavities and curves in walls. Actually this 
way serves two goals. Architectural goal: to lessen the building weight. Ornamental goal: which cuts the boring that the spectator feels in it on the extended walls for long distance and because of that curves? The human took the idea of making the stalactite in walls corners and in the high parts of it.

The researcher sees that difference of the opinions about the origin of that architecture element. While (Alshaaffe) didn't give us a specific definition of the stalactite in determination of its origin. He had been mentioned that it transferred to the BYZANTINE architecture in an Islamic shape. corner curves which we'd rather call it stalactite which it looks like a hollow curve has a tip from half circle dome from its inside and outside and sometimes two poles carry it and its Iraqi Islamic phenomenon, first example appeared of it was the history of the construction of samara and also exist in the public door of palace of MUTASIM which called by ALJUSAQ AL KHAKANI.

In another position that there was an architectural phenomenon which is called (the corner stalactites) which are placed on dropdown square to transferee it to octagon or circle that stand on it the down edge of the dome for example/ SASANIPALACES it said that they are belong to the third and fifth centuries

Also it said that some stalactites are taken from the downs and ups.

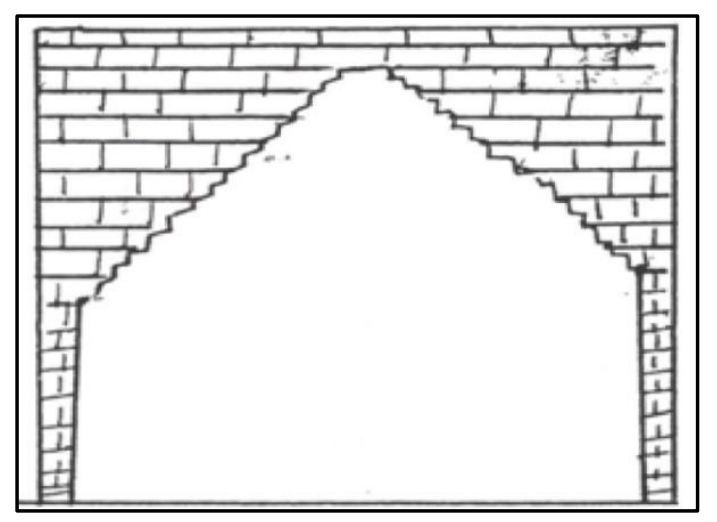

Figure 1. Architectural element from UR city south of Iraq

According to what architecture competent and archeology decorative architectural ornament that make group of curves which can be classified into gradual classes as in the conical domes. Which indicates that these elements had been used in a very wide way in Islamic building especially the ones that had been built in Iraq? Because older of these stalactites belong to the ABBASID period. And from this we can say that the stalactite in its structure that made of arranged curves in sequence classes one above the other it's actually Arabic innovation in Islamic eras. And this phenomenon may belong to Iraqi origin. The innovation is not that big deal with Muslims, which their innovation contained all kind of arts and industry. it might be the curve after the architecture developed it and transferred it into sequence classes one above the other and he thought that naming came not in suitable place so how it hangings one above the other and probably which widely had been used in Islamic architecture is the same element. Which the Islamic artist was inspired by the idea to make stalactites especially the curves that the stalactites are made of it which they're usually be in knots and they differ from a stalactite to another according to the artistic need or what the architect sees suitable to make that stalactites, or maybe the lobular knot in particular inspired the idea and it's building according to the clear similarities between the two elements, that means the idea of the lobular knot came from the system of the knots .because the Muslim architect tried to find a softness and flexibility in the knots sequence movement in these kind of knots which are half circle. And from that these idea came out from knot shapes that revealed from the ancient Iraqi civilization 25000.

1.It's worth mentioning to talk about the lobular knots as a shape and structure to establish the relationship that connect between them. The lobular knot that its edges had been cut as alternative halves circle or made of halves segments which look like the edge of the oyster, and its simplest kinds is the tripartite segments knot that made of three halves circles, and the ornamental lobular 
knot saved its geometrical shape after its development and spreading in different Arabic architectural

2.We can collect the most important kinds of the used stalactites in all architectural Arab Islamic schools:

3.The stalactite that has two centers which looks like the fife sharpened knot.

4.The sharpened stalactites which represent the painted knot on the corner 30degrees

5.The big stalactites with two centers or sharpened for a structural purpose.

6.The stalactites of internal knot which are made of one mass in the beginning of the knot position.

7.The complex stalactites between more than one ways of drawing.

8.The hanging stalactite that usually lies inside the knot.

9. The conical stalactite.

10. The using of the new materials especially the concrete cancelled the artistic treatments for the roofs held, basements and domes. In the line with these materials, a real upheaval happened that cancelled many of the inherited customs in the traditional architectural embroider such as Muslim architecture, but the door will be opened to find a new style to employment and artistic directions for this kind of architectural elements . Might be in the gradual structural building or in volumetric roofing to the partial coverage elements in a way that makes from these rare elements an inspiration source for a generation of new architects in their creativity to continue devoting and existence of the elements specialties of the Islamic architecture.

\subsection{Stalactites functions}

Architectural functions: it considers for stalactites in its accurate geometrical structure in classes same are under the other some. And it helps of implementing apportionment of the mass weight wherever it found in building classes. the stalactite divide the mass into small parts based on one another and it's one of the supreme elements that allows convergence and connectivity between flat and curved surfaces for transferring form square to octagon then to circle in the dome or for transferring from flat to another in minarets basins or arcana.

11. Ornamental function: there is a geometrical structure for the stalactite which is stand on to essential principle: matching and similarities and also stands on the principle which control the things movement in nature they are: pheasant and contradiction, all of them leave movement, change, interest, existent and the activity of designed and embodiment and awesome artistic work.

The matching in the stalactite leads to duplication in the shape which means the duplications in the curves and duplications those stalactites is made from. The duplication exists in the visual art by matching accept the difference in the things position. So the relationship between the elements at that point is measured by one dimension which is the space separator.

While the similarities in the stalactite exists in the concord which represents all similar units in one element (all the curves and publications in one architectural element which is the stalactite that is the cover of the dome or minarets basin or the top of hollow niche and the units are compatible when they share in one element or one object.

The geometrical foundation to build the stalactites:

The stalactite in all its different kinds is one of the geometrical shapes, which the Arab Muslim artist created in the way of its using and manifest a high capacity in its installation and distribution and coordination. The Arab ancient architects left samples of the stalactite in ABABBASED building which challenge engineer's ability in modern era.

The Muslim artist considered the square is the flat shape of the proportionality and consistency because it achieves balanced relationships integrated, stable and simple between its parts inspired by the Islamic religion essence that depended on simplicity, balance and stability. Of the basis of the square is the balanced abstract shape. It depended prorated numeral value of the string length which equals the (sqrt) (2) - (414/1) essential base for the relationships of the proportionality and consistency between dimension. the Muslim architect was undergoing process of design for any mass or decorative of using this base according to measure and beauty by using simple machines to determine square string and intersection points of the location which means that the style of 
working of this base depends on the artistic sense of the architect in the second numeral value (414/ 1) so he chooses the most consistent and beautiful prorates for him. And uses the best geometrical way in designing and implementation one of the most important features of stalactites that are the best clear examples of three dimensional geometry forming and allow for convergence and connectivity between curved and flat surfaces like the transferring from square into octagon then to the dome or practically stalactite which consists sculpted or collected units to make a specific pattern we can collect these units in many different ways which differ from the building shape that exist in .

\subsection{The geometrical structure of the minarets stalactites}

The geometrical structure of the knotted stalactites doesn't differ from the other stalactites in domes but the ones in the minarets look mirrored which means the gradual process starts from the circular base and ends in a polygonal base as in schema.

It stands on geometrical sequentially foundations in astral shape and make it from 24 tips, that had been made because of the trunk division of the cylindrical minaret shape into 24 equaled unite that form the beginning of the geometrical sequentially for the minarets stalactites. The curves of the first line stand on the base of 16 tips which caused by the intersection of four regular squares that restrict eight equal distances between them. The four tips are the concentration points of the second line curves and we find in it divers from of different curves in the size and shape which their tips are the concentration points of the last line.

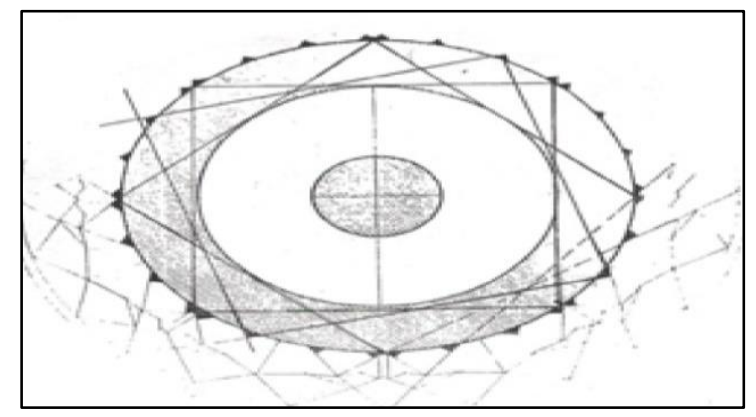

Figure 2. Horizontal section for stalactites in one of Mosque in old Baghdad (Alkhafafeen Mosque)

While the geometrical structure of the (alshaikh maaroof) minaret similar to the (alkhafafeen) stalactites structure with a simple difference that caused by the variance of lines and of the curves shapes as in (schema no: 2).

\section{METHODOLOGY}

\subsection{The research method:}

The researcher depended on analytical and descriptive approach in order to achieve the achievement of the research goals.

The research community and its sample:

Research community includes the stalactite that lies in minarets of Baghdad mosques archaeological, she depended on the field's visits and on documented and picture sources.

Due the difficulties of collecting all kinds of the existed stalactites in the minarets of Baghdad mosques archaeological during the last Abbasid period. She decided to make this study limited to the three minarets and adopted as research samples which are: (Alkhalafaa) mosque minaret. 


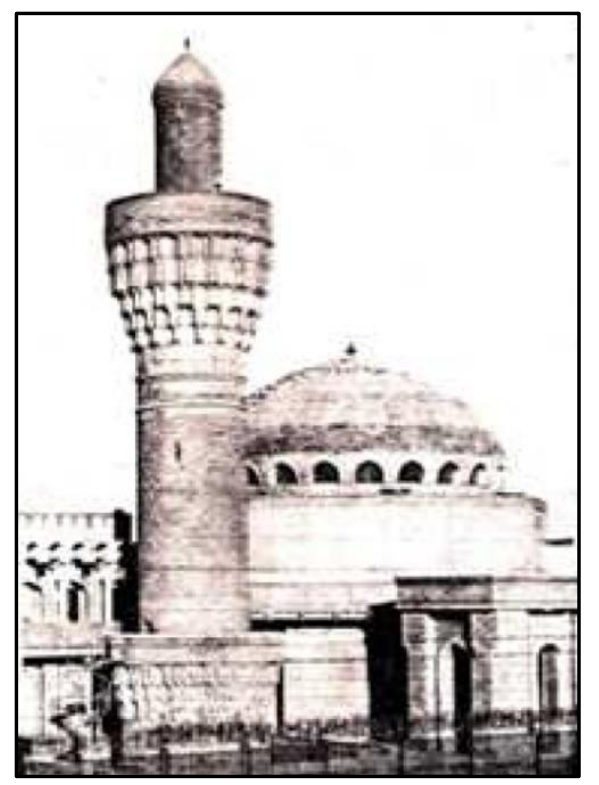

Figure 3. (Alkhalafaa Mosque) Baghdad - Iraq

\subsection{The Analysis :(Alkhalafaa) mosque minaret: General description:}

This minaret is one of the larger and longer minarets its height $35 \mathrm{~m}$, it had been built by different bricks in shapes and sizes according to its places the minaret composed of a base that contain 12 ribs and ribbed balcony above it and goes up from the ground in about $3,5 \mathrm{~m}$.

The cylindrical trunk lies above the balcony while under it there are two holes for the 2 ladders penetrate the trunk and lead to the second balcony up in the minaret which has a cylindrical shape and stands on a base that has layers of stalactites which are previously ornamented look at (the schema below):

So this minaret featured in its trunk length that based on equivalence and symmetry, it's one of the individual minarets kinds that's why we see that the architect found a kind of proportionality and consistently between trunk length which includes a group of local ornaments that called the attics ornaments which are sculptured on the bricks sunken digging, and between the stalactites and its development and completing in new direction that manifested with accuracy some of its parts as in the stalactites that hanging as suspended stalagmite in caves' ceilings .

But the minaret stalactites start in an ornamental line with brick paving in a way which called the vertical paving, above it and beyond it a salience looks like the twisted rope which called headband and disparity between the lines number and curves number in the line. It's a sort of finding a kind proportionality between trunk height and the lines number. That's why the architect worked on increasing in that lines number to be super perfection and the proportionality and consistently between the length and number of the stalactites lines, plus six lines egress to prepare the ground between the basin circle and the trunk.

The minaret had been left empty of paring between the glassed bricks and the ornament because of the difficulties that caused by the small sizes of the units which are made from. Its huge number, dents sharpness of it and the salience which requires a high level of professionally, occurrence and careful. While the plant decoration that represented by the Arabic securitization, which had been arranged like fillings outside the stalactites. The most important element is the palm fan and its complex shapes which are twisted crossed and symmetrical and also there are decoration stalactites of the upper terrace edge which is spread as in (schema 3) for its several layers and its shapes variation.

The shadow and light have the big importance because they need opposing ingredients for each other when they fall on surfaces. We found the light effects in a direct way and sometimes in direct, the direct way has a shade on the ground, but we care about the indirect way. because it represent 
the fallen shadow, but the shadow that lies against the light that gives a beauty value for the stalactites while the artificial lighting during the night has an artistic meaning of the minaret and its stalactites to reveal how to perform constructively in working like realization with the color plus salience of the stalactites units or the ornament to give a real meaning of the vision to make the spectator touches the architectural body features.

While the Muslim architect tries to benefit the ore, color and ornament to enrich the surface exploited the friendly values of the nature ores surfaces to give beauty value, variation and depth on the trunk surface.

\section{CONCLUSION}

The minarets stalactites in the architecture building characterized by a privacy for its modernity and the uniqueness of other civilizations plus the structural treatments and decorative ones that joined an available space data of the stalactite within every part from parts of the total area. The idea of stalactites emergency connected with the stages of gradual transition from flat surfaces that have the four corners to curved surfaces that fit with the concentration of the lower edges. The aesthetic standards: (system, proportionality, golden ratio, repetition unity and diversity) that the Muslim architect sought to approach and deport as starters that the visible action established on it (stalactites) in Arabic Islamic architecture. Ornaments employment in all its kinds in decoration of some minarets stalactites came to give designing prospects related with (the Muslim architect himself) and his skills, experience in developing the ornamental ingredients with requirement of architectural space and its specification within one formed structure that gathers them all.

\section{Acknowledgment}

This work was supported by University of Baghdad; the author will like to thank for their support.

\section{First A. Author (AlAttabi, furat J. Hassan)}

BA in Arabic calligraphy and Islamic decoration - college of Fine Arts - University of Baghdad Iraq - 1999, Master of Arabic calligraphy and Islamic decoration - Faculty of Fine Arts - University of Baghdad 2004.- PhD Design / college of Design - Donghua University - Shanghai - China - 2014.

\section{Publishing papers:}

- The design relations and the role of it making the idea for fashion design - IEEE 12th International Conference on Computer-Aided Industrial Design \& Conceptual Design- China Chinese , 2010.

- Artistic Techniques for Developing Creativity in Design - Applied Mechanics and Materials, Vols. 397, China / English, 2011.

- $\quad$ The Design between Creation and Methodology - UK / English, 2012.

- Artistic Influences Analysis of Iraqi National Costumes - China / Textile engineering, ICTEM- Chinese. 2013.

- Environmental art and its relationship with the product and technical design, 14th, international conference, Russia , 2015. English.

- Goggle scholar @ Alattabi furat J. Hassan, Professor of art and design, Verified email at cofarts.uobaghdad.edu.iq

\section{References}

[1] Shafei, Farid, Arab Islamic Architecture, Egypt, 1970. p. 53.

[2] Gustavo, Le Pen, Arab Civilization, Cairo, 1969. P. 205.

[3] Abdul Aziz, Marzooq, Islamic History and Characteristics Art, Baghdad, Asa'ad Press, 1965, p. 184.

[4] Hassan, Zaki Muhammad, the Arts of Islam, Authorization Committee press, Cairo, 1948, p. 48. 
[5] Fikri, Ahmad, the Mosque of the Mosque in Qairowan, Al Ma'arif Press, Cairo, 1936, p. 48.

[6] Bahnasi, Afif, Encyclopedia of Art History and Architecture, Cairo (ND), p. 398.

[7] Marzouk, Abdul Aziz, Islamic decorative arts in the Ottoman era, Baghdad, (ND) p. 73.

[8] Auf, Abdul Rahman, proportionality in Islamic architecture, Afaq Arabia journal, vol. 2, tenth year, Baghdad, 1984, p.64.

[9] Al-Ani, Aladdin, Minarets of Peace City, Faculty of Arts, doctoral dissertation, University of Baghdad, Baghdad, 1992, p.115.

[10] Salman, Issa, Arab Islamic Buildings, Dar Al-Rasheed press, Baghdad, 1982, p.33. 